\title{
Topologia das Agências Bancárias da Região Metropolitana de Manaus
}

\author{
Topology of Bank Branches in the Metropolitan Region of Manaus
}

Topología de las Sucursales Bancarias en la Región Metropolitana de Manaus

Fredson Bernardino Araújo da Silva ${ }^{1}$

https://orcid.org/0000-0002-1897-2655

Kamila de Oliveira Craveira ${ }^{2}$

https://orcid.org/0000-0002-5323-0163

Tatiana Schor ${ }^{3}$

https://orcid.org/0000-0002-6220-3626

\begin{abstract}
RESUMO: A topologia das agências bancárias permitiu compreender a lógica territorial mais visível da questão bancária e do acesso ao crédito, além de pontuar a distribuição das agências como produto de uma razão corporativa na atuação no espaço. Portanto, o objetivo é discutir a topologia das agências bancárias na Região Metropolitana de Manaus (RMM). Para isso, identificou-se brevemente as centralidades da atividade financeira no contexto nacional, destacando os recursos tecnológicos voltados para a atuação presencial. Tomando como estudo de caso a RMM, procuramos analisar a distribuição da rede bancária, tendo as agências como fixos geográficos principais; e, a partir do que foi levantado em teoria e empiricamente, verificou-se a hipótese de que a lógica territorial da rede bancária regional está associada à metropolização do espaço. O que se obteve como resultado é que ocorre uma concentração da atividade bancária no interior da metrópole (núcleo metropolitano), havendo a formação de um eixo financeiro para atender uma fração da população mais rica de Manaus. No quadro regional, Manaus concentra cerca de $70 \%$ das agências bancárias, tendo Manacapuru (eixo sul) e Itacoatiara (eixo leste) como subcentros da rede no que se refere à espacialização desse dado.
\end{abstract}

PALAVRAS-CHAVE: Topologia. Agência bancária. Região Metropolitana de Manaus. Metropolização do espaço.

\footnotetext{
${ }^{1}$ Mestrando em Geografia pela Universidade Federal do Amazonas. E-mail: fbernardino1997@gmail.com.

${ }^{2}$ Mestranda em Geografia pela Universidade Federal do Amazonas. E-mail: kamoliveira29@gmail.com.

3 Doutorado em Ciência Ambiental (2005) pela Universidade de São Paulo. Docente do Departamento de Geografia e da Pós-Graduação em Geografia da Universidade Federal do Amazonas. E-mail: tschor@ufam.edu.br.
} 


\begin{abstract}
The topology of bank branches allowed us to understand the most visible territorial logic of the banking issue and access to credit, in addition to pointing out the distribution of branches as a product of a corporate reason for operating in space. Therefore, the objective is to discuss the topology of bank branches in the Metropolitan Region of Manaus (RMM). For this, the centralities of financial activity in the national context were briefly identified, highlighting the technological resources aimed at in-person work. Taking the RMM as a case study, we sought to analyze the distribution of the banking network, having the branches as the main geographic locations; and, based on what was raised in theory and empirically, the hypothesis was verified that the territorial logic of the regional banking network is associated with the metropolization of space. What was obtained as a result is that there is a concentration of banking activity within the metropolis (metropolitan nucleus), with the formation of a financial axis to serve a fraction of the richest population in Manaus. In the regional framework, Manaus concentrates around $70 \%$ of bank branches, with Manacapuru (south axis) and Itacoatiara (east axis) as subcenters of the network in terms of spatialization of this data.
\end{abstract}

KEYWORDS: Topology. Banking agencies. Metropolitan Region of Manaus. Metropolization of space.

RESUMEN: La topología de sucursales bancarias permitió comprender la lógica territorial más visible del tema bancario y el acceso al crédito, además de señalar la distribución de sucursales como producto de una razón corporativa para operar en el espacio. Por tanto, el objetivo es discutir la topología de las sucursales bancarias en la Región Metropolitana de Manaus (RMM). Para ello, se identificaron brevemente las centralidades de la actividad financiera en el contexto nacional, destacando los recursos tecnológicos destinados al trabajo presencial. Tomando la RMM como caso de estudio, se buscó analizar la distribución de la red bancaria, teniendo las sucursales como principales ubicaciones geográficas; $y$, a partir de lo planteado teórica y empíricamente, se verificó la hipótesis de que la lógica territorial de la red bancaria regional está asociada a la metropolización del espacio. Lo que se obtuvo como resultado es que existe una concentración de la actividad bancaria dentro de la metrópoli (núcleo metropolitano), con la conformación de un eje financiero para atender a una fracción de la población más rica de Manaus. En el marco regional, Manaus concentra alrededor del $70 \%$ de las sucursales bancarias, siendo Manacapuru (eje sur) e Itacoatiara (eje este) como subcentros de la red en términos de espacialización de estos datos.

PALABRAS-CLAVE: Topología. Sucursal bancaria. Región Metropolitana de Manaus. Metropolización del espacio.

\title{
INTRODUÇÃO
}

No contexto do território brasileiro, há disparidades em várias dimensões de entendimento da instância social, como também na questão financeira. As políticas territoriais promovidas pelo Estado há muito pretendem amenizar as desigualdades regionais tendo a Região Amazônica como um desses focos. Por exemplo, na questão financeira, o Banco da Amazônia aparece como estratégia para isso. Outro ponto que se leva em consideração é a baixa integração da Amazônia Ocidental com o Brasil meridional, particularmente no que se refere aos fluxos rodoviários. Diante disso, opções como os modelos de região metropolitana e zona franca foram adotados para Manaus e sua região de influência, no Estado do Amazonas, como meio de articulação nacional e desenvolvimento regional. 
O processo de metropolização do espaço tem como uma das principais características a reestruturação produtiva que influi no território a fim de promover um rearranjo nos objetos e nas ações vinculadas aos grupos sociais. Essa reestruturação tem um forte caráter de descentralização dos grandes centros, especialmente do que é relativo à atuação das corporações no espaço. O que ocorre é um movimento que rompe com a concentração da metrópole (núcleo metropolitano) em direção às regiões de influência, isto somente é possível por conta do mundo remoto que é dado num paradigma informacional e financeiro. Para tanto, uma das questões centrais é a gestão do território tendo em vista uma apropriação corporativa do espaço, como é o caso dos bancos que, por meio de uma estratégia territorial a partir das agências, consomem e modelam o espaço urbano e metropolitano, vide o caso da Região Metropolitana de Manaus (RMM).

Nessa perspectiva, o objetivo desta proposta é de discutir, sob o recorte da RMM, a topologia das agências bancárias e, assim, considerar a gestão do território pelos agentes modeladores e consumidores do espaço urbano associados ao fenômeno financeiro.

Para isso, a pesquisa se deu pelo levantamento de acervo bibliográfico e construção teórica sobre a temática. Para a área estudo, levantou-se dados quantitativos nos sites oficiais do Censo do IBGE de 2010 (IBGE, 2010a), havendo também consulta sobre as diferentes legendas/empresas bancárias presentes: Banco do Brasil, Banco da Amazônia, Caixa Econômica Federal, Banco Santander, Branco Bradesco e Banco Itaú, além das localizações disponibilizadas pelo Google Maps para mapeamento das agências bancárias a fim de elucidar sobre a estrutura territorial. Propõe-se também uma reflexão sobre o processo de metropolização do espaço e a distribuição das agências bancárias.

Assim, ainda em termos introdutórios, segue-se uma relação da apreensão teórica acerca da produção geográfica do conhecimento no que tange o objeto de estudo, seguido de breve contextualização do processo de institucionalização do ente jurídico-territorial que constitui a RMM. A discussão apresentada nos resultados parte de um panorama das disparidades da gestão do território, a fim de dar base para a discussão regional. $\mathrm{Na}$ espacialização das agências bancárias, observa-se a articulação da prática dos bancos como agente corporativo. E, por fim, aborda-se a distribuição bancária tendo em vista as possíveis vinculações com o processo de metropolização do espaço.

\section{O ESPAÇO GEOGRÁFICO E ELEMENTOS INICIAIS DA QUESTÃO DAS FINANÇAS}

A expressão da dinâmica social é evidenciada pelas ações que não se desassociam do espaço construído, isto é, dos objetos. É neste quadro que Santos $(1994,2006)$ articula a (re)formação do espaço geográfico ao se basear num meio técnico-científico e informacional 
do período atual, onde o trabalho é subsidiado pelos avanços em pesquisas e 0 desenvolvimento da globalização.

Esse meio geográfico atual marca-se por uma tecnociência que se move predominantemente para atender as demandas de uma sociedade de mercado, como ocorre com o setor bancário. Este, por sua vez, é situado num cenário do circuito superior da economia, ou seja, atividades bancárias e financeiras, comércios, indústrias e serviços modernos, frequentemente orientados para a exportação, bem como alta sofisticação técnica e burocrática (SANTOS, 2008). O termo "burocracia" ganha conotação de ineficiência ou rigidez administrativa, por muito negativa. Porém, no sentido weberiano, refere-se à delimitação de funções, seleção de funcionários e critérios técnicoadministrativos e/ou racionais voltados para execução de dado sistema.

O setor bancário passa por uma expansão, especialmente com investimentos em canais de autoatendimento e canais digitais (internet banking, mobile banking e fintechs) conforme demonstram vários estudos como Cataia (2003), Contel (2009, 2011), Oliveira (2019) e, com maior ênfase, Warf (2017). Esses estudos apontam para um tipo de expansão onde os objetos instalados de oferta de serviço como as agências bancárias são enfraquecidas, uma vez que as tecnologias da informação abrem "telepossibilidades" à topologia bancária. Trata-se das possibilidades provenientes da densidade técnica e dos meios comunicacionais mais sofisticados também sintetizados por Alves (2015), Guerim (2017), Robbins (2006) e Santos (2018).

Considera-se ainda que as ferramentas de mobile e internet banking coordenam uma ubiquidade, ou seja, uma capacidade de acesso em todos os lugares, porém, ressalta-se que dependem de uma base material para operação e manutenção. Não obstante, as fintechs ganham maior importância. O surgimento ou entrada em novos mercados destas depende de "determinações tecnológicas", além da necessidade de uma tendência de seguridade/estabilidade econômica e de pouco acesso ao crédito pelas empresas já instaladas no mercado visado (HADDAD; HORNUF, 2019). Os elementos mencionados internet banking, mobile banking e fintechs - perfazem uma tecnosfera que impacta o mundo das finanças, entretanto não são o foco principal nesta oportunidade.

Assim, nossa proposta é de uma abordagem sobre a topologia bancária regional, tratando-se da distribuição das agências bancárias enquanto objetos geográficos com o poder de influir na dinâmica das finanças, o que resulta num entendimento específico das dimensões subnacionais. Neste estudo, tem-se o foco na questão bancária no contexto da RMM, o que permite compreender a configuração espacial dos objetos e agentes de um dos mais importantes sistemas do setor terciário na região amazônica. Em síntese, a topologia é 
um instrumento que pode elucidar a "[...] manifestação mais visível de uma lógica territorial" (SILVEIRA, 2009, p. 69).

Como exemplo de proposta de estudo semelhante em compreender a lógica do capital e de empresas de um setor bancário regional, aponta-se Fresca (2017) com a opção de vinculação do fenômeno urbano como controlador da dinâmica das finanças no norte do Paraná. Sobre o Estado do Amazonas, onde está inserida a RMM, tem-se os estudos de Alves, Oliveira e Moura (2011) e de Costa (2017) que versam sobre o quantitativo das agências bancárias, além de proporem ensaios sobre a distribuição espacial financeira nos municípios, especialmente do interior do estado. Ainda na questão amazonense, de forma mais tangencial, aponta-se Souza (2018) que comenta a importância do crédito habitacional como ferramenta de facilitação do Estado como ator do "espaço físico" no município de Parintins. Todavia, não constam trabalhos sobre a geografia das finanças tendo como cenário-foco a RMM.

\section{BREVE CONTEXTO SOBRE A METROPOLIZAÇÃO DO ESPAÇO NA AMAZÔNIA OCIDENTAL: O CASO DA INSTITUCIONALIZAÇÃO DA RMM}

A RMM passa por um processo de metropolização do espaço que contrapõe uma "lógica clássica". Conforme Lima (2014) e Sousa (2013) a RMM apresenta uma metropolização do espaço por uma indução tendo o Estado articulado com os promotores imobiliários como principal agente e que elege as áreas prioritárias ao crescimento da metrópole (Figura 1).

Em 2009, por um discurso de integração dentro do cenário regional, são inseridos mais cinco, obtendo-se a maior área metropolitana brasileira e, ao mesmo tempo, a de menor densidade demográfica. A síntese desse processo está nas normativas produzidas pelo poder político e ratificadas pelo poder jurídico (Quadro 01).

Por meio da estrutura jurídica, obtém-se a institucionalização da RMM. Os direcionamentos do crescimento da metrópole são definidos a partir do instrumento denominado Plano Diretor Integrado da RMM (AMAZONAS, 2010) que pontua o 'Portal do Solimões', isto é, o vetor sul à metrópole - Iranduba e Manacapuru - como o setor prioritário para integração junto à metrópole. Então, como pontuado por Silva (2019), a "RMM jurídica" precede a "RMM socioespacializada" enquanto fato metropolitano contíguo materializado, mas que está em vias de se realizar com a conurbação no nexo ManausIranduba onde, por exemplo, os fluxos de movimento pendular aparecem cada vez mais em consistência (EHNERT, 2011). Ressalta-se, no entanto, que a conurbação não é o único fato espacial a se considerar para analisar a materialidade da metropolização do espaço; leva-se, com maior peso, a intensidade de fluxo para se verificar o referido processo. 
Figura 1 - Localização da Região Metropolitana de Manaus

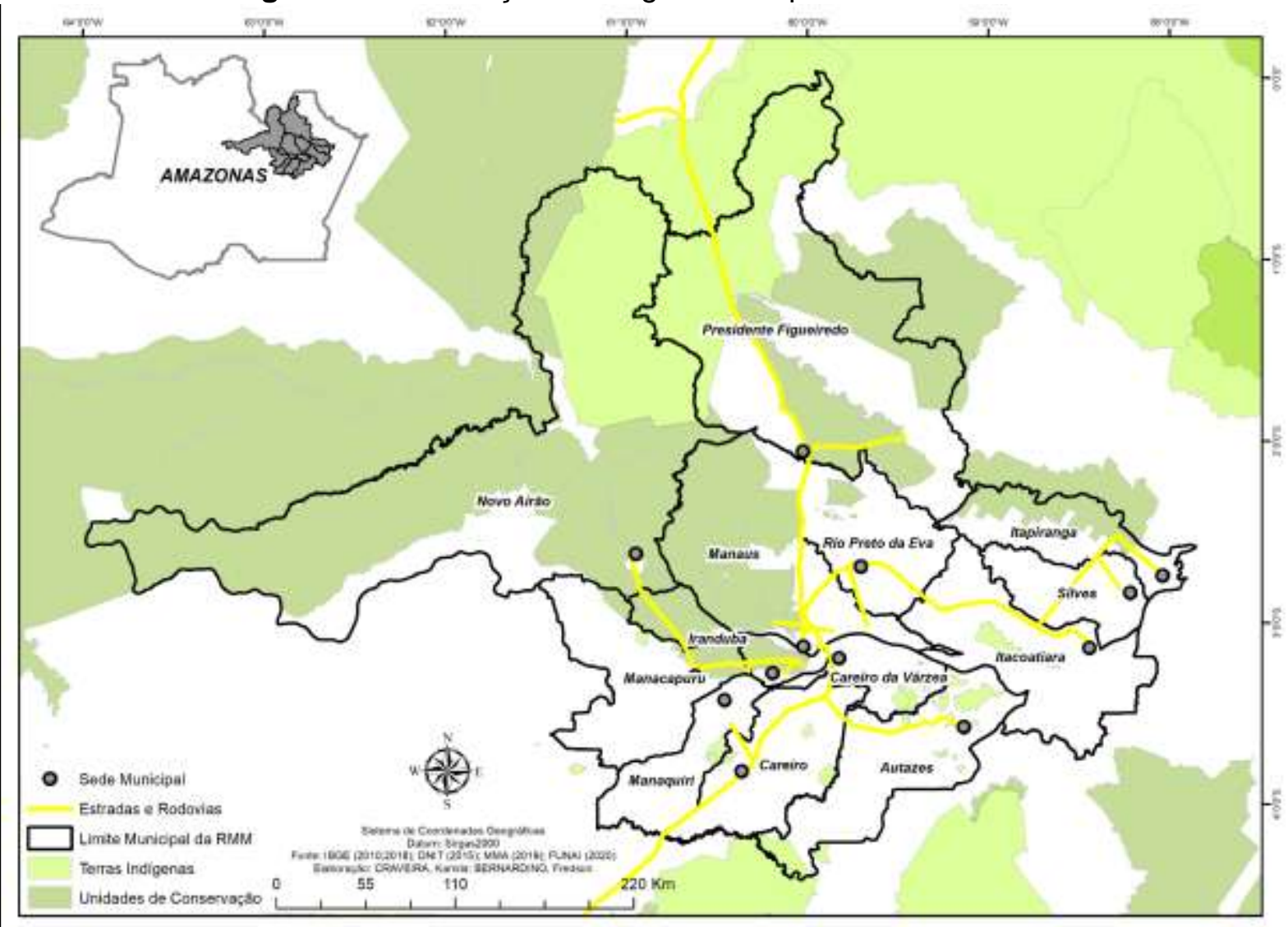

Fonte: IBGE (2010b, 2018a), BRASIL (2015), BRASIL (2020).

Quadro 01 - Periodização da institucionalização da Região Metropolitana de Manaus

\begin{tabular}{|l|l|}
\hline \multicolumn{1}{|c|}{ Normativa } & \multicolumn{1}{c|}{ Municipalidade(s) } \\
\hline $\begin{array}{l}\text { Lei Complementar oㅜ 52 de } 30 \text { de } \\
\text { maio de } 2007\end{array}$ & $\begin{array}{l}\text { Manaus, Iranduba, Novo Airão, Presidente Figueiredo, Rio } \\
\text { Preto, Itacoatiara, Careiro da Várzea }\end{array}$ \\
\hline $\begin{array}{l}\text { Lei Complementar no } 59, \text { de } 27 \text { de } \\
\text { dezembro de } 2007\end{array}$ & Manacapuru \\
\hline Lei Promulgada ํㅜ 64 de 2009 & Itapiranga, Silves, Autazes, Careiro, Manaquiri \\
\hline
\end{tabular}

Fonte: Silva (2019).

Após a institucionalização em 2007 e a incorporação de mais municípios em 2009, tem-se, em 2011, a entrega da Ponte Jornalista Phelippe Daou, que rompe com a descontinuidade até então promovida pelo Rio Negro no trecho Manaus-Iranduba, além de crescimento da metrópole. O Estado como agente-hegemônico, especialmente o governo do Estado do Amazonas, associa-se com outros agentes, com destaque aos promotores imobiliários e os proprietários fundiários, para promover a intensificação na articulação metropolitana no trecho da metrópole Manaus ao Município de Iranduba (LIMA, 2014; SOUSA, 2013). 


\section{PRINCÍPIOS PARA DISPARIDADES DAS FINANÇAS NO BRASIL}

A não equidade do território pode ser avaliada por diversos indicadores. A desigualdade sobre a rede urbana brasileira é pauta de debate desde a geoeconomia e a geopolítica clássicas. Entenda-se aqui geoeconomia e geopolítica como sistemas de (re)produção e intercâmbio material e imaterial dados na concepção territorial. A geopolítica refere-se principalmente a todas as relações do Estado e demais atores sociais na interação do território. Nessa lógica, a geoeconomia aparece relativa à participação dos atores econômicos privados mas que também podem compreender a pertinência do Estado para dinâmica territorial no contexto de instância social. Nesse ponto, Fresca (2017) argumenta que há uma correlação entre as redes urbana e bancária, o que colocaria a Amazônia Ocidental como um dos pontos fracos da rede nacional (Figura 2).

Figura 2 - Mapa das principais cidades da hierarquia urbana do Brasil em 2018, conforme as Regiões de Influência das Cidades

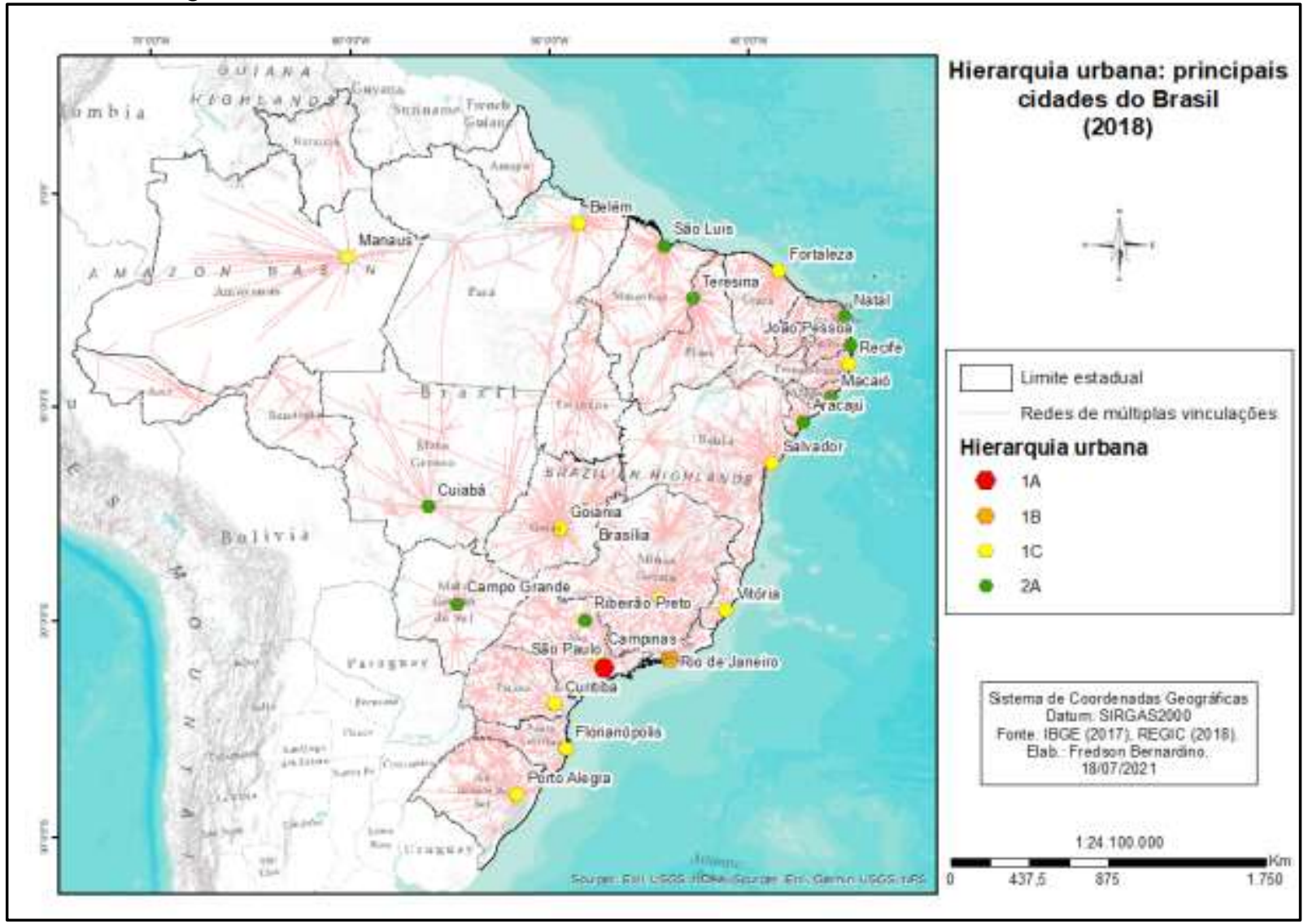

Fonte: IBGE $(2017,2018 \mathrm{~b})$.

Corrêa (1989) já aponta a ocorrência de concentração financeira e de centros empresariais no Brasil meridional e/ou litorâneo - ascensão de São Paulo como centro metropolitano financeiro nacional — em detrimento de outras regiões e que perdura 
parcialmente até hoje (Figura 2). Não obstante, o autor também identifica um processo de monopolização das legendas bancárias.

Em 2007, oito eram os bancos de nível nacional, isto é, instituições bancárias que atuam em mais de 20 Unidades Federativas (IBGE, 2007): Banco do Brasil e Caixa Econômica Federal, como estatais e Bradesco, Itaú, HSBC, ABN-AMRO-Real, Unibanco e Rural, como privados (IBGE, 2007). Atualmente, há uma acentuação da concentração a nível nacional, e tem-se apenas cinco legendas: Banco do Brasil e Caixa Econômica Federal; Bradesco, Itaú e Santander.

Cataia (2001) aponta as desigualdades da tecnificação no território brasileiro. Tanto este quanto Corrêa (1989) colocam a Amazônia como uma espécie de "fronteira do capital" (financeiro) entre várias fronteiras no contexto brasileiro. No que se refere ao Amazonas e que pode ser estendido para os estados próximos, essa limitação fica mais latente na parte mais a oeste, sobre a qual Nogueira (2007, p. 161) chega a provocar: "aqui começa o Brasil" (Figura 3).

Figura 3 - Disparidades de fluxos financeiros e digitais no Brasil em 2019, conforme Regiões de Influência das Cidades

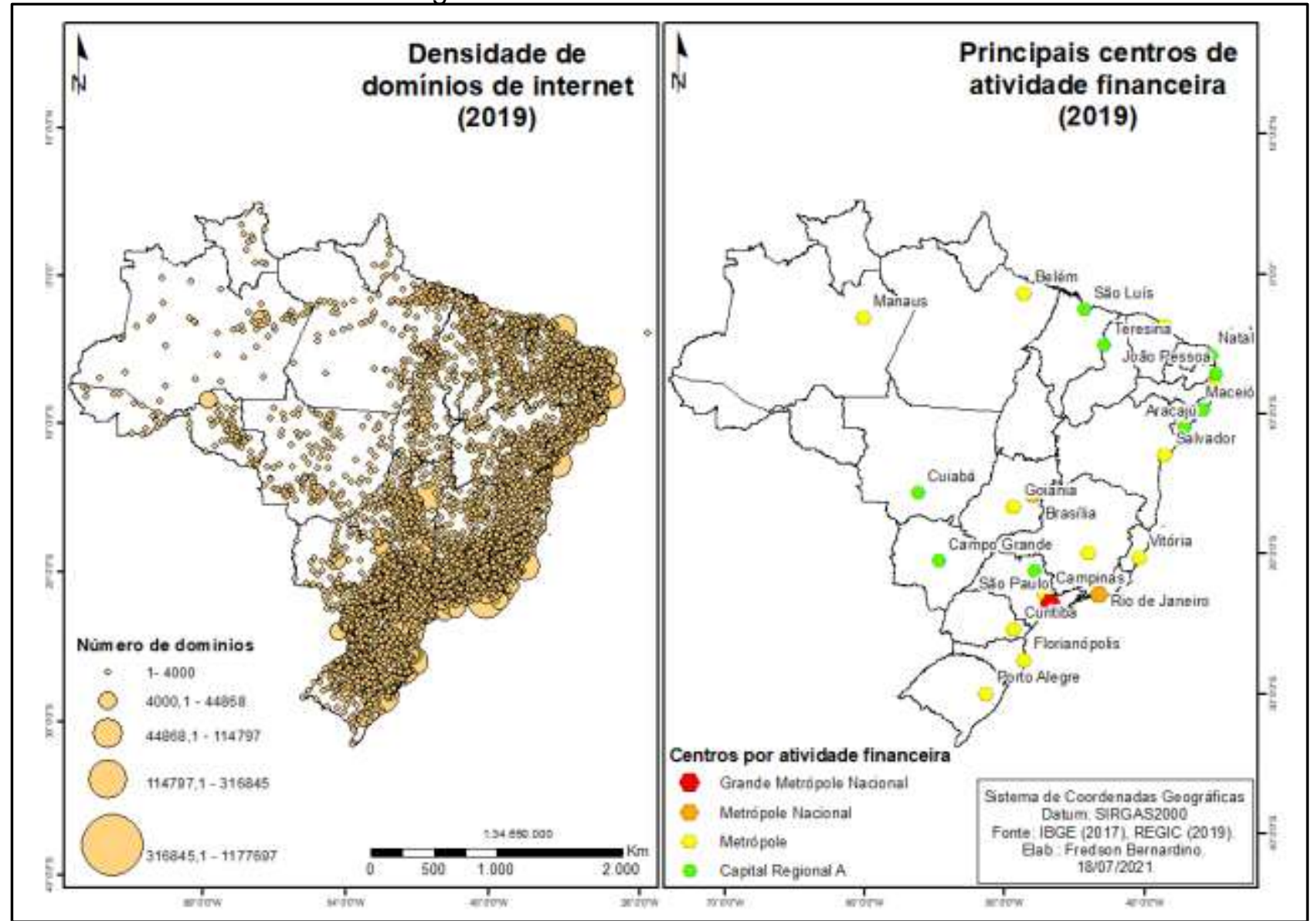

Fonte: IBGE $(2017,2019)$. 
Domínio de internet é o termo utilizado pelo IBGE para o registro de endereço digital. Esse dado é utilizado como indicador de acesso à internet. De forma mais atual, o que se apreende é uma distribuição da atividade financeira que, de certa forma, ainda segue esse padrão na Amazônia Ocidental, tendo baixa similaridade com o Brasil meridional. Essa disparidade pode ser explicada ao se levar em conta a dificuldade de instalação técnica, no que se refere a uma base material operante. Esse arranjo espacial, por consequência, inviabiliza uma hipercapilaridade na região. E "hipercapilaridade", refere-se aos novos objetos técnicos que facilitam os serviços financeiros e a ubiquidade do território (CONTEL, 2009, 2011). Na prática, no que se refere às finanças, essa hipercapilaridade é a capacidade de supervisão e execução com relação ao sistema financeiro independentemente da localização geográfica do interessado. Portanto, a questão central é a base material que ainda apresenta um estágio de desenvolvimento em comparação com o restante do Brasil, observável na Figura 3.

Por fim, ainda se considera a relação geral de disparidades na gestão do território brasileiro. Por gestão do território, entende-se como "[...] faceta da gestão econômica, política e social, a ela estando subordinada, mas também a condicionando. É a dimensão espacial do processo geral de gestão, confinando-se ao espaço sob controle de um Estado ou de uma dada empresa" (CORRÊA, 1992, p. 1). Sobre os fluxos de gestão, observa-se a concentração no eixo Rio-São Paulo relacionada com a dinâmica econômica, além da importância política de Brasília representando a centralidade associada à estrutura de poder do Estado brasileiro (Figura 4).

A priori, esse cenário contextualiza a área de estudo como uma região deprimida dentro da lógica de gestão do território nacional. Esses princípios apresentados e outros pontuam as disparidades no território nacional. Todavia, sob a escala geográfica da Amazônia Legal, as metrópoles de Manaus e Belém se apresentam como principais centralidades, mas Belém ainda tem maior capacidade de articulação com as centralidades da escala nacional. Essa diferença influi na heterogeneidade socioespacial entre dois eixos: Belém (Amazônia Oriental) e Manaus (Amazônia Ocidental). 


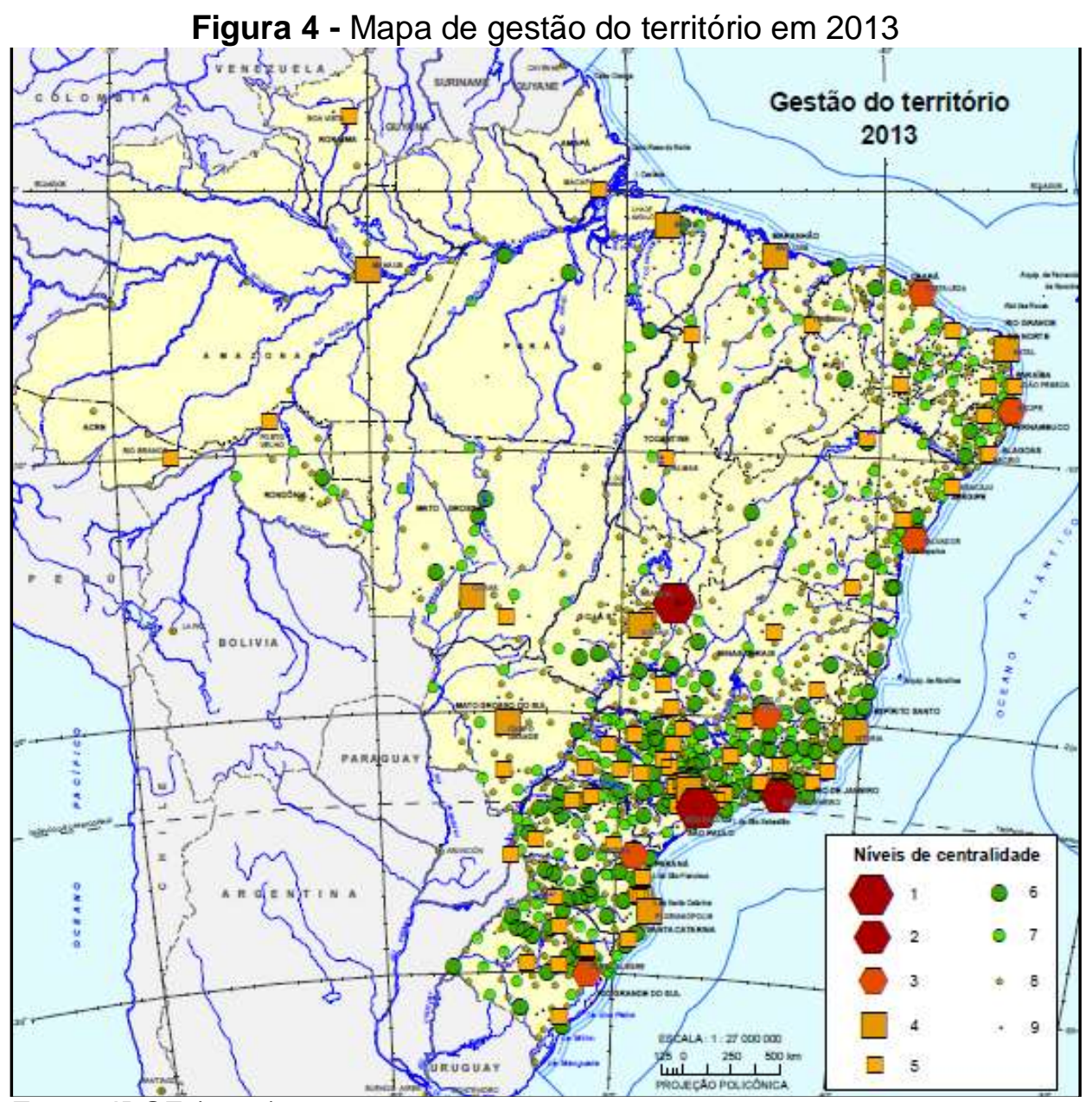

Fonte: IBGE (2014).

\section{FIXOS GEOGRÁFICOS: AGÊNCIAS BANCÁRIAS NA RMM}

É a partir do Plano Real, instalado em 1994, como coloca Contel (2011), que a finança e a informação ganham destaque para o espaço geográfico nacional. A hipercapilaridade ganhara importância superando um modelo baseado na operação de agências bancárias, isto é, fixos geográficos. Todavia, na escala da Amazônia Ocidental, com exceção da metrópole de Manaus, a questão técnica voltada para os fluxos de informação e finanças se encontra em fase de desenvolvimento, ou seja, há uma centralidade financeira em Manaus, mas que não apresenta pulverização no restante do território (Figura 5). Por outro lado, no contexto nacional, a razão de hipercapilaridade está posta e, de forma genérica, pulverizada pelo território.

Quanto à metrópole Manaus, há concentração de agências bancárias nas Zonas Centro-Sul e Sul, tendo o eixo das paralelas Avenidas Djalma Batista e Constantino Nery como coração financeiro da metrópole Manaus, como evidenciado na Figura 5. Esta centralidade que ocorre no eixo citado é comum em menor grau nas outras zonas da cidade, 
isto porque as agências estão sediadas próximas umas às outras e geralmente numa mesma via principal que se torna um verdadeiro eixo financeiro.

Figura 5 - Agências bancárias da metrópole Manaus em 2019

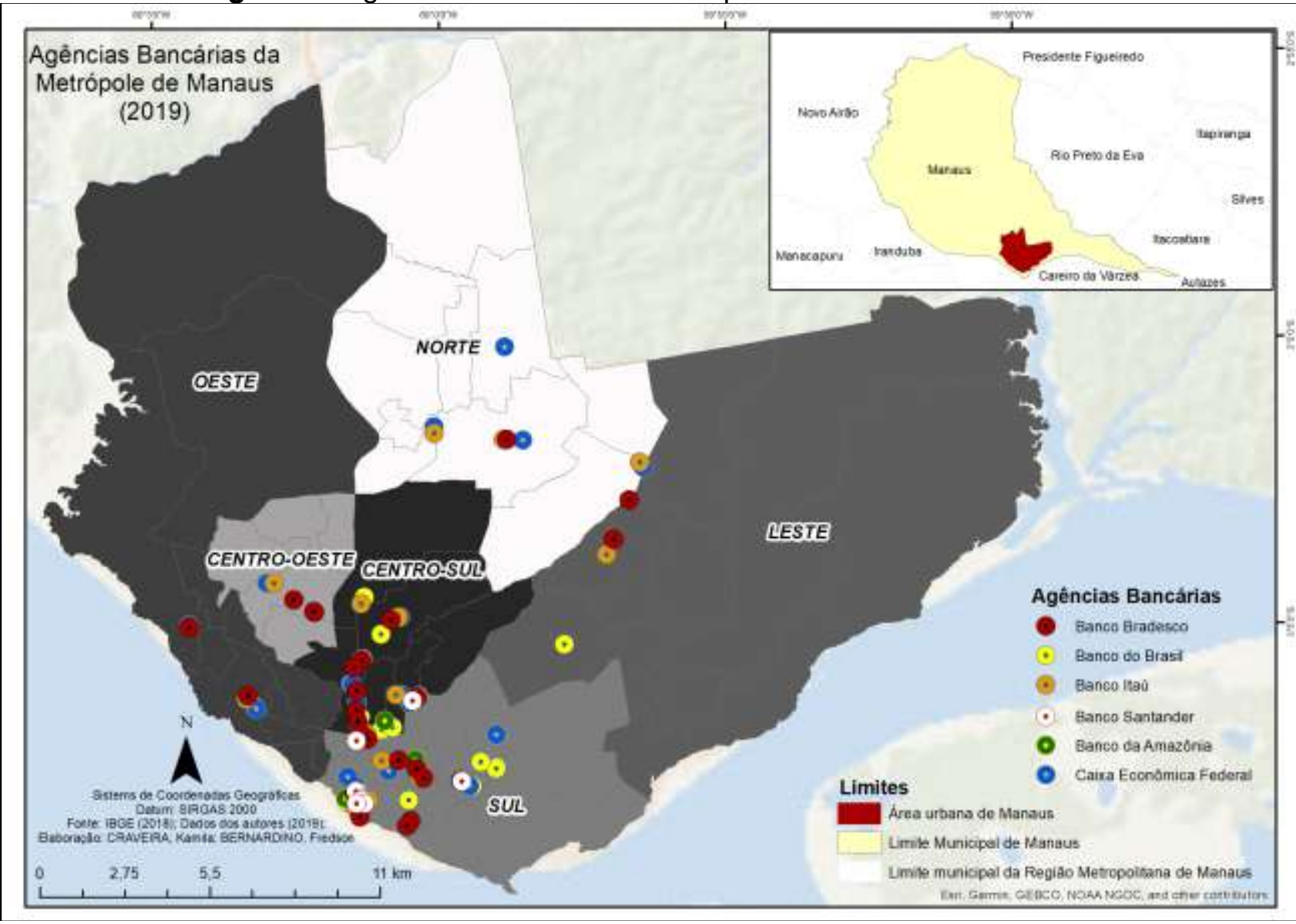

Fonte: adaptado IBGE (2018c).

A lógica corporativa de atuação do setor bancário está posta, pois as Zonas Norte e Leste são as mais populosas, mas não apresentam distribuição de agência de forma correlata à satisfação da demanda social. Trata-se, em geral, de um grupo de socialmente excluídos, tendo em vista a pouca acumulação derivada da baixa renda, o que gera baixa capacidade de investimento e, consequente, dificuldade relativa de tomada de crédito (Figura 6). Embora, de acordo com Montenegro e Contel (2017), ressaltar-se que os grupos de baixa renda a nível nacional passaram por um processo de maior acesso a bens e serviços devido, entre outros fatores, à facilitação de crédito e, com efeito, um "endividamento sistemático das famílias" no território brasileiro (MONTENEGRO; CONTEL, 2017, p. 123).

Esse arranjo espacial, na lógica corporativa, não assegura o lucro para oferta de serviço numa rede bancária mais densa e/ou extensa nas zonas mais deprimidas socioeconomicamente da metrópole Manaus como são os casos das Zonas Norte e Leste. 
Para essas zonas, o canal de autoatendimento (caixa eletrônico) é a oferta em que a população faz a maioria das operações, especialmente saque.

Figura 6 - Distribuição de Renda por bairro na metrópole de Manaus em 2010

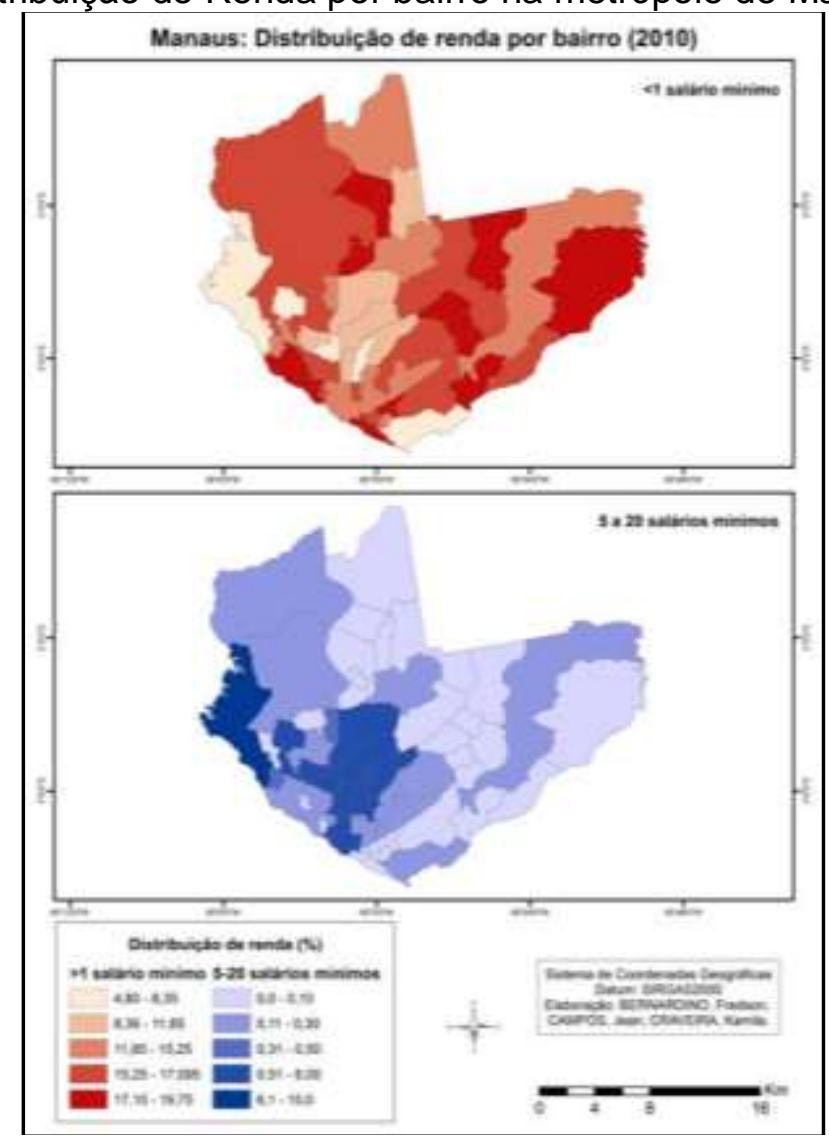

Fonte: IBGE (2010a).

Na Figura 6 evidencia-se a distribuição de renda na área urbana do município de Manaus. Uma vez espacializada, é possível verificar como a população com renda inferior a um salário mínimo está distribuída mais próxima ao perímetro da área urbana, com destaque para os bairros localizados na Zona Leste onde $19,75 \%$ da população sinalizou este valor e a zona onde há menor cobertura de serviços relativos às agências bancárias na metrópole.

A região mais central, onde se concentra a rede bancária, também apresenta concentração da riqueza. O coração financeiro da metrópole também sedia boa parte da renda entre cinco a 20 salários mínimos. O bairro Ponta Negra, no extremo oeste da Zona Oeste, é destacável pela concentração da riqueza.

A seguir, procura-se realizar um levantamento sobre a distribuição das agências bancárias por legenda dentro da lógica regional. $\mathrm{Na}$ RMM, todas as agências bancárias estão localizadas nas sedes municipais, isto é, os distritos e demais aglomerados da malha urbana se encontram sem a operação desses fixos geográficos. 
O primeiro banco analisado é o Banco da Amazônia, trata-se do único banco não nacional atuante, foi criado na década de 1940 como política de base para viabilização e fortalecimento da extração do látex. Foi, década após década, um mecanismo estatal de gestão do território na Amazônia brasileira e, mesmo com o declínio da atividade primeira produção de látex - a que se destinou sua criação, modificou-se ao longo do tempo para atender as necessidades de estímulo e administração dos objetos dispostos no espaço bem como às dinâmicas oriundas deles e criadas a partir dos mesmos. Atualmente, existem cinco agências dispostas na RMM, sendo sua maioria - três agências bancárias localizada na metrópole (Figura 7).

Figura 7 - Mapa das agências bancárias dos (A) Banco da Amazônia e (B) Banco Bradesco na Região Metropolitana de Manaus em 2019
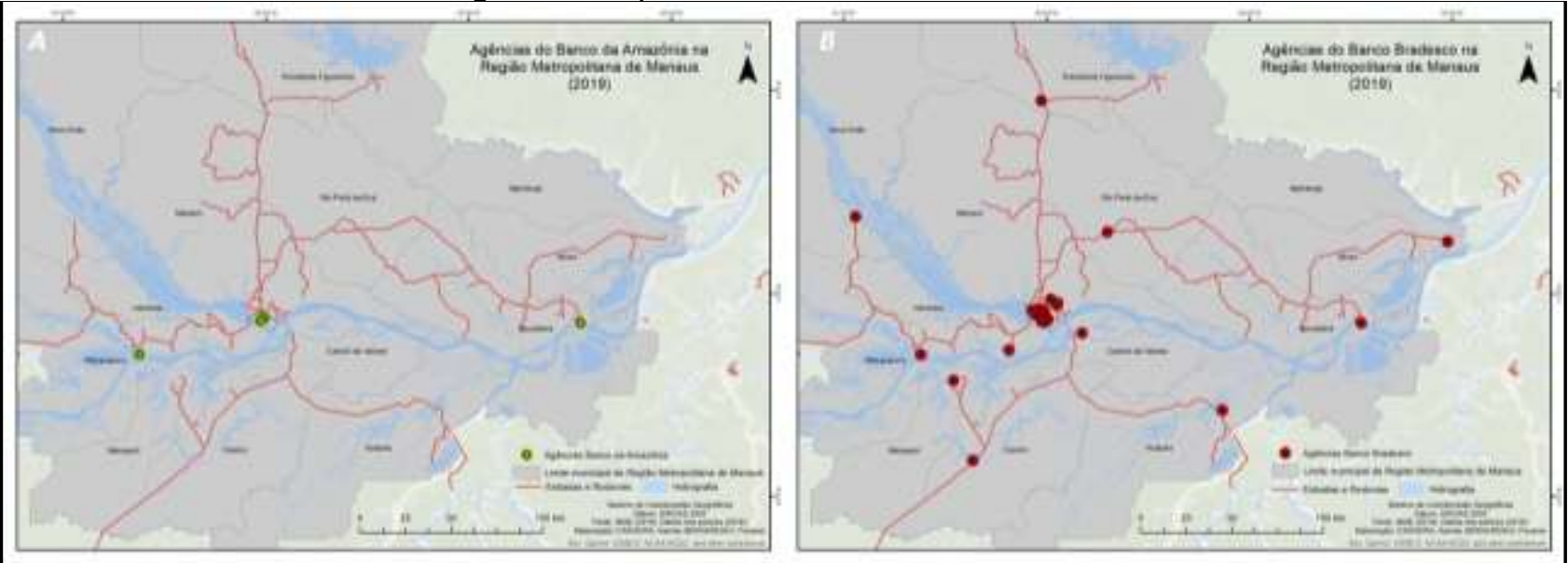

Fonte: adaptado IBGE (2018c).

O Banco Bradesco é o maior expoente no que se refere à distribuição da franquia no recorte delimitado. Ao todo, são 40 agências espalhadas por 12 dos 13 municípios que compõem a RMM. A rede de agências do Banco Bradesco corresponde a $31 \%$ do total de agências mapeadas na região.

Mesmo sem o registro de agência em Silves, único município da RMM sem resultados quanto a presença dessa modalidade, o Bradesco, conforme sua plataforma digital, disponibiliza caixas eletrônicos 24 Horas na sede da municipalidade, estando presente mesmo que de forma mais pontual e ainda assim significativa, demonstrando que a distribuição é numericamente díspar na RMM e, no entanto, a presença do banco aparece sob novas formas como no autoatendimento.

O Banco Santander conta com nove agências, representando cerca de 6,9\% do total de agências mapeadas. Apenas uma agência do Santander está localizada fora da metrópole Manaus, baseando-se na sede municipal de Itacoatiara (Figura 8). 
Figura 8 - Mapa das agências bancárias dos A) Banco Santander e B) Banco Itaú na Região Metropolitana de Manaus em 2019

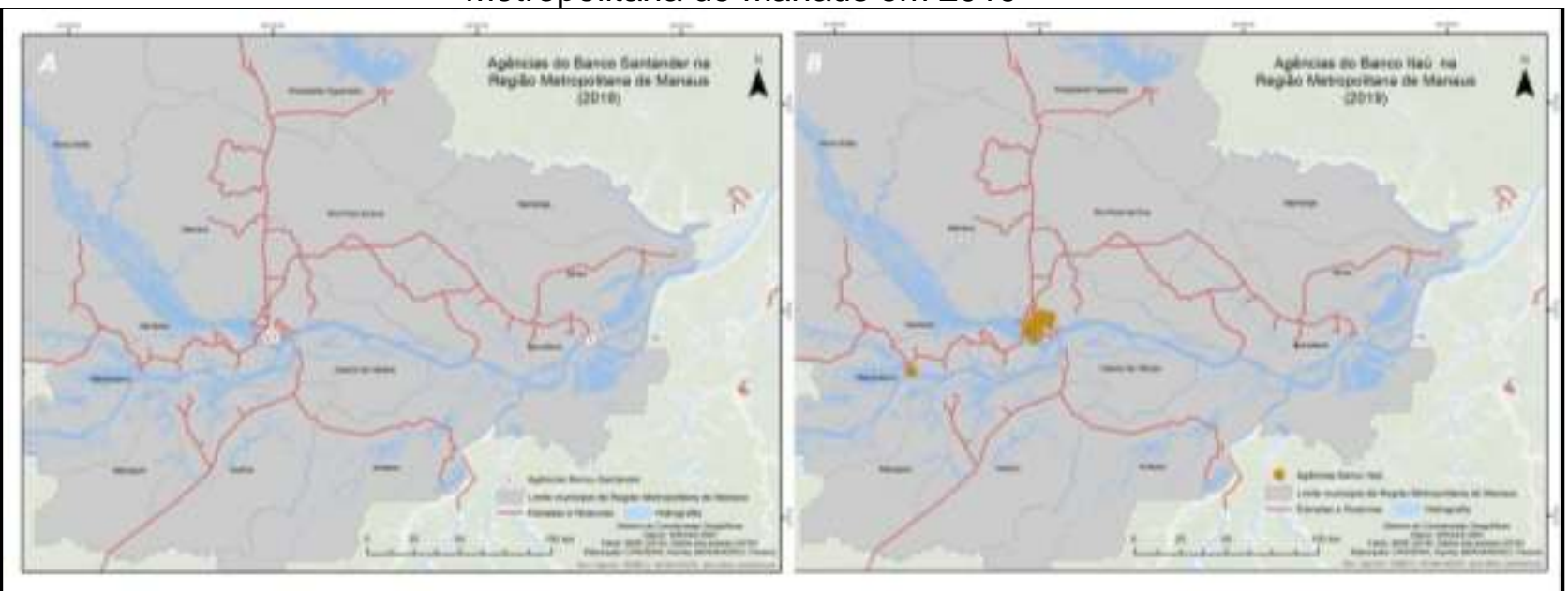

Fonte: adaptado IBGE (2018c).

Sobre o Banco Itaú, ao todo, foram contabilizadas 20 agências bancárias, sendo 19 sediadas em Manaus e a última situada na sede de Manacapuru, que é ligada à Manaus pela rodovia AM-010. O Banco Itaú se concentra basicamente na área urbana de Manaus, apresentando uma única agência bancária localizada fora da metrópole.

O Banco do Brasil representa o terceiro banco com agências ativas na RMM sendo responsável por pouco mais de $20 \%$ das agências catalogadas, concentradas em sete municípios da Região Metropolitana (Figura 9).

Figura 9 - Mapa das agências bancárias dos A) Banco do Brasil e da B) Caixa Econômica Federal na Região Metropolitana de Manaus em 2019

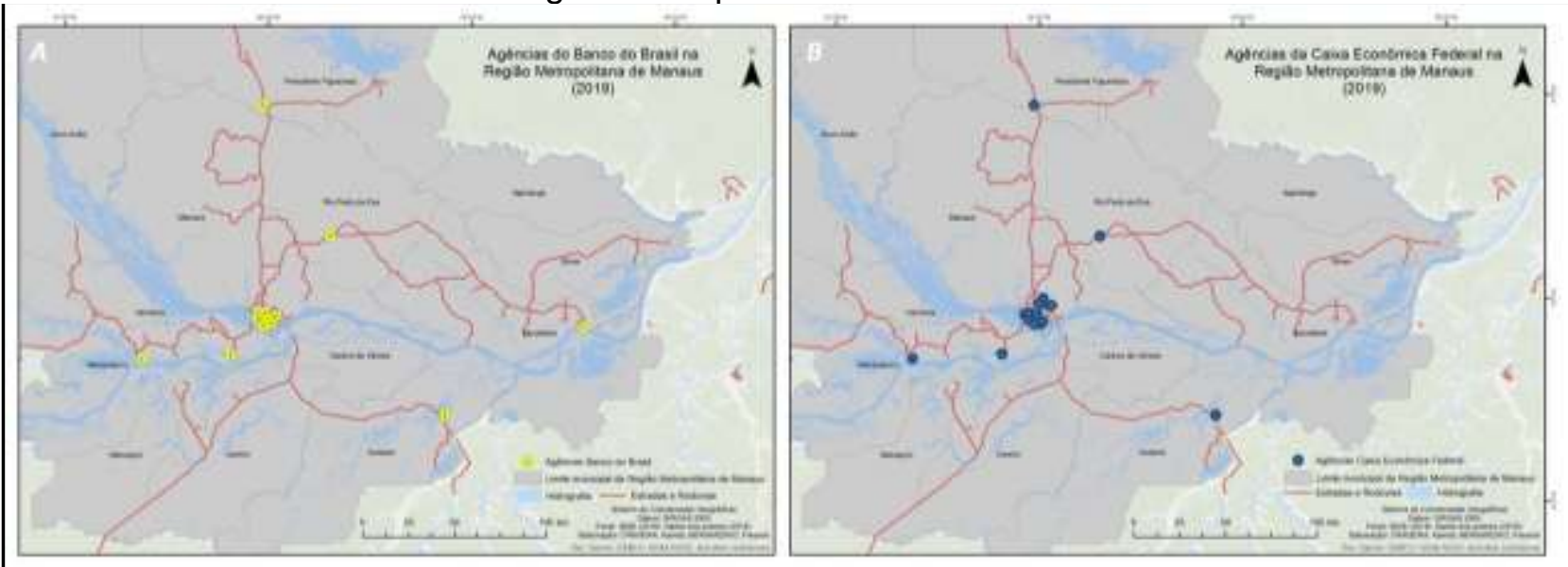

Fonte: adaptado IBGE (2018c).

A Caixa Econômica Federal é o banco estatal mais representativo, possui 28 agências no total, o que representa $21,7 \%$ dos registros mapeados. Está presente em cinco municípios além da metrópole Manaus, que possui 22 agências, como demonstra a Figura 9. Cita-se ainda as Lotéricas que realizam uma série de funções comuns da agência 
bancária da Caixa Econômica Federal e que também influi na topologia, cabendo, inclusive, um estudo específico sobre tal estratégia territorial sob a perspectiva do planejamento do Estado.

\section{GESTÃO DO TERRITÓRIO, BANCOS E METROPOLIZAÇÃO DO ESPAÇO NA RMM}

Ao se analisar a topologia bancária regional foi revelada uma estratégia que coaduna com o apontado em outro estudo de caso realizado por Oliveira (2019). Essa estratégia é dada por uma dimensão onde ocorre uma distribuição bancária desigual intra-metrópole, porém ainda é mais latente no recorte da RMM jurídica, pois 100 das 129 agências (77,5\%) da RMM estão na área urbana de Manaus (Figura 10).

Figura 10 - Concentração das agências bancárias na Região Metropolitana de Manaus em

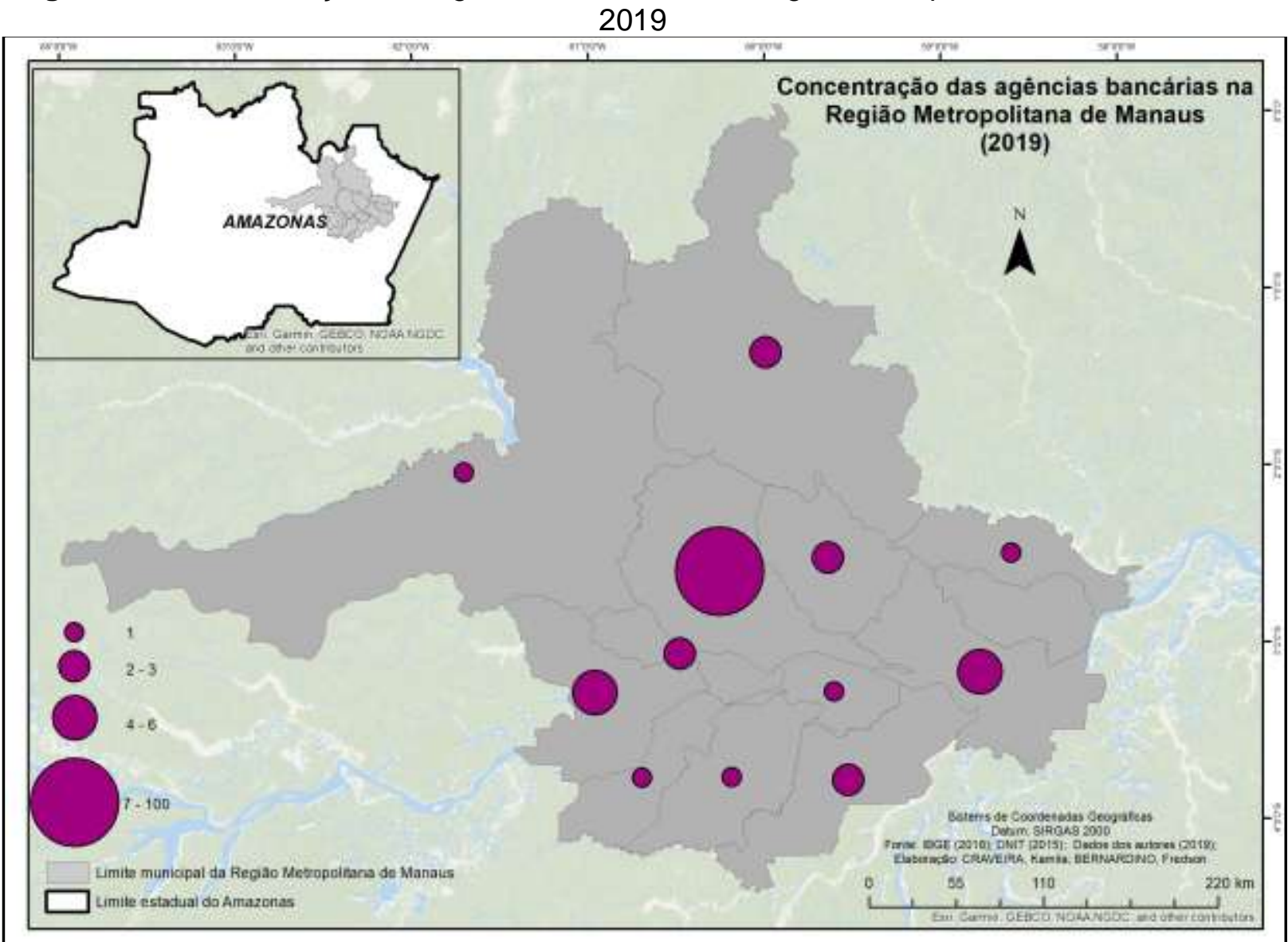

Fonte: adaptado IBGE (2018c).

Não foi verificada a indução do processo de metropolização do espaço pelo Estado vinculado aos atores financeiros como ocorre com outros modeladores do espaço urbano (CORRÊA, 2002), em especial os promotores imobiliários, demonstrado por Lima (2014), Silva (2019) e Sousa (2013). 
Tendo em vista a metrópole Manaus como área primária da atividade bancária, e o Portal do Solimões (vetor sul: Iranduba e Manacapuru) se apresenta como área secundária da lógica bancária da RMM, mas não é a única. O vetor leste à metrópole, com foco em Itacoatiara, também aparece em emergência, ou seja, como outra área secundária.

No contexto bancário, a metropolização do espaço da RMM ainda apresenta grandes desafios. Tem-se Silves, no vetor leste, como principal setor deprimido do território, não apresentando nenhuma agência bancária de nenhuma legenda.

Ao se tratar da temática bancária a nível regional para a área de estudo, salvo o estudo de Alves, Oliveira e Moura (2011) sobre a distribuição bancária com foco na rede urbana, não há publicações da Geografia sobre a questão. Esse cenário torna o Amazonas como um flanco de abordagens relativas à geografia das finanças. Sobre o estudo, os autores identificam maior variedade de legendas nas proximidades da capital do estado do Amazonas, e são destacados: Banco do Brasil, Bradesco e Banco da Amazônia.

Costa (2017) também chama atenção sobre a importância da base material para a operação dos "equipamentos financeiros". A distribuição e acesso à tecnologia como internet e infraestrutura é fator controlador para a presença de agências bancárias e demais equipamentos financeiros. Este, em nosso entender, é o elemento técnico-chave para explicar o quadro financeiro da RMM.

\section{CONSIDERAÇÕES FINAIS}

As disparidades do território são dadas em várias formas e abordadas em diversas escalas pelos geógrafos e pelo Estado. O caso da geografia das finanças e das informações depende de uma base material de operação. Essa base se dinamiza a partir de fixos geográficos, estes articulam objetos técnicos que, na questão regional brasileira, ainda se observa como em processo de integração.

A produção do espaço (urbano) promovido pelos atores financeiros normalmente pouco se preocupa com a questão social. O crédito é visto como mero fim de mais-valia. Entretanto, entendemos o exercício intelectual ou o conhecimento em lato sensu como ferramentas para revelar a natureza de estruturas sociais que podem ser ressignificadas.

O que chamamos de geografia das finanças vem cada vez mais ao protagonismo, pois a financeirização do espaço por meio da espoliação do trabalho, vide a uberização das relações sociais e, no caso brasileiro, a fragilização da rede de seguridade social ganha força. O crédito é matéria e o acesso a ele é fator que promove disparidades nas diversas escalas de sociedade/espaço. Ainda podemos considerar o caráter particular para a região estudada, pois para a Região Amazônia muito se vincula um jargão de "desenvolvimento 
sustentável", e trata-se de um modelo de produtivo que somente pode ser alcançado a partir de um plano nacional de desenvolvimento que vincule as propostas de zoneamentos ecológico-econômicos para as escalas menores.

Sobre a área de estudo, a dificuldade da tomada de dados para se traçar correlações mais consistentes entre as redes urbanas e bancária se coloca como a demanda em maior emergência. Poucas são as produções geográficas focadas numa geografia do financeiro no Estado do Amazonas, somente tivemos acesso a um artigo e um relatório de iniciação científica.

\section{REFERÊNCIAS}

ALVES, Caio Zarino Jorge. A topologia dos bancos de investimento no Brasil: primazia urbana e formação do complexo corporativo metropolitano de São Paulo. Dissertação (Mestrado em Geografia Humana) - Faculdade de Filosofia, Letras e Ciências Humanas da Universidade de São Paulo, São Paulo, 2015.

ALVES, Juliana A.; OLIVEIRA, José Aldemir de; MOURA, Luciana Karoline F. de. A rede bancária no Estado do Amazonas: algumas notas sobre sua distribuição espacial. Revista Geográfica de América Central, Heredia, v. 2, n. 47E, p. 1-15, 2011.

AMAZONAS. Plano Diretor Integrado da Região Metropolitana de Manaus (PDIRMM). Manaus: [s. I.], 2010.

BRASIL. Ministério da Infraestrutura. Departamento Nacional de Infraestrutura de Transportes. Sistema Nacional de Viação (SNV). 2015. Disponível em: http://servicos.dnit.gov.br/vgeo. Acesso em: 18 fev. 2020.

BRASIL. Ministério da Justiça e Segurança Pública. Fundação Nacional do Índio. Terras indígenas - Shape. 2020. Disponível em: Shape (funai.gov.br). Acesso em: 18 fev. 2020.

CATAIA, Márcio A. As desigualdades e a tecnificação do território brasileiro. In: CARLOS, Ana Fani Alessandri (org.). Ensaios de Geografia contemporânea. São Paulo: Hucitec, 2001. p. 170177.

CATAIA, Márcio A. Alienação dos territórios frente aos processos de globalização econômica. In: ENCUENTRO DE GEÓGRAFOS DE AMERICA LATINA, 9., Mérida. Anais [...]. Mérida: [s. n.], 2003. p. 1-7.

CONTEL, Fabio Betioli. Espaço geográfico, sistema bancário e a hipercapilaridade do crédito no Brasil. Caderno CRH, Salvador, v. 22, n. 55, p. 119-134, 2009.

CONTEL, Fabio Betioli. Território e finanças. Técnicas, normas e topologias bancárias no Brasil. São Paulo: Annablume, 2011.

CORRÊA, Roberto Lobato. Concentração bancária e os centros de gestão do território.

Revista Brasileira de Geografia, Rio de Janeiro, v. 51, n. 2, p. 17-32, 1989. Disponível em: https://biblioteca.ibge.gov.br/visualizacao/periodicos/115/rbg_1989_v51_n2.pdf. Acesso em: 18 fev. 2020.

CORRÊA, Roberto Lobato. Corporação, práticas espaciais e gestão do território. Anuário do IGeo, Rio de Janeiro, v. 15, p. 35-41, 1992. Disponível em:

https://revistas.ufrj.br/index.php/aigeo/article/view/5934. Acesso em: 21 abr. 2020.

CORRÊA, Roberto Lobato. O espaço urbano. São Paulo: Ática, 2002. 
COSTA, Cláudio R. C. A distribuição espacial dos equipamentos financeiros nas cidades situadas no interior do estado do Amazonas. Manaus: Universidade Federal do Amazonas, 2017.

EHNERT, Alexandre Ricardo von. A região metropolitana de Manaus e as migrações pendulares. 2011. Dissertação (Mestrado em Geografia Humana) - Faculdade de Filosofia, Letras e Ciências Humanas, Universidade de São Paulo, São Paulo, 2011.

FRESCA, Tânia M. Rede urbana, rede bancária e aspectos da topologia do sistema financeiro. Geousp: Espaço e Tempo, São Paulo, v. 21, n. 2, p. 443-461, ago. 2017.

GUERIM, Thiago Gonçalves Marques. Território e regionalismo bancário: topologia e estratégica geoeconômica do Banestes/ES. 2017. Dissertação (Mestrado em Geografia Humana) - Faculdade de Filosofia, Letras e Ciências Humanas, Universidade de São Paulo, São Paulo, 2017.

HADDAD, Christian; HORNUF, Lars. The emergence of the global fintech market: economic and technological determinants. Small Business Economics, Dordrechtv, v. 53, p. 81-105, 2019.

IBGE. Regiões de influência das cidades: (REGIC). Rio de Janeiro: IBGE, 2007.

IBGE. Censo 2010. Rio de Janeiro: IBGE, 2010a. Disponível em: IBGE | Censo 2010. Acesso em: 18 fev. 2020.

IBGE. Malha municipal. Rio de Janeiro: IBGE, 2010b. Disponível em: Malha Municipal | IBGE. Acesso em: 18 fev. 2020.

IBGE. Gestão do território: 2014. Rio de Janeiro: IBGE, 2014. Disponível em: Gestão do Território | IBGE. Acesso em: 18 fev. 2020.

IBGE. Malha municipal. Rio de Janeiro: IBGE, 2017. Disponível em: Malha Municipal | IBGE. Acesso em: 18 fev. 2020.

IBGE. Malha territorial. Rio de Janeiro: IBGE, 2018a. Disponível: Malhas territoriais | IBGE. Acesso em: 18 fev. 2020.

IBGE. Regiões de influência das cidades (REGIC). Rio de Janeiro: IBGE, 2018b.

IBGE. Amazonas: unidades da Federação. Rio de Janeiro: IBGE, 2018c. Disponível: https://geoftp.ibge.gov.br/organizacao_do_territorio/malhas_territoriais/malhas_municipais/m unicipio_2010/am/am_unidades_da_federacao.zip. Acesso em: $18 \mathrm{fev} .2020$.

IBGE. Regiões de influência das cidades (REGIC): resultados definitivos. 2019.

Disponível em: Index of

/organizacao_do_territorio/divisao_regional/regioes_de_influencia_das_cidades/Regioes_de influencia_das_cidades_2018_Resultados_definitivos/base_vetorial (ibge.gov.br). Acesso em: 18 fev. 2020.

LIMA, Marcos Castro de. Quando o amanhã vem ontem: a institucionalização da região metropolitana de Manaus e a indução ao processo de metropolização do espaço na Amazônia ocidental. 2014. Tese (Doutorado em Geografia Humana) - Faculdade de Filosofia, Letras e Ciências Humanas, Universidade de São Paulo, São Paulo, 2014.

MONTENEGRO, Marina; CONTEL, Fabio B. Financeirização do território e novos nexos entre pobreza e consumo na metrópole de São Paulo. Eure, Santiago de Chile, v. 43, n. 130, p. 115139, sept. 2017.

NOGUEIRA, Ricardo J. B. Amazonas: a divisão da "monstruosidade geográfica". Manaus: Edua, 2007. 
OLIVEIRA, Juliana S. de. O paradigma técnico bancário no século XXI: a rede de atendimento híbrida e as estratégias dos bancos na cidade de Campinas/SP. 2019. Dissertação (Mestrado em Geografia) - Instituto de Geociências, Universidade Estadual de Campinas, Campinas, 2019.

ROBBINS, Eric. Location, location, location: has electronic banking affected the importance of bank location? Financial Industry, Pespectives, Kansas, p.1-12, Sept. 2006.

SANTOS, Fábio Brito dos. Topologia bancária e economia do setor público: a atuação do Banco do Brasil em Alagoas e a importância das folhas de pagamento das prefeituras. 2018. Dissertação (Mestrado em Geografia Humana) - Faculdade de Filosofia, Letras e Ciências Humanas, Universidade de São Paulo, São Paulo, 2018.

SANTOS, Milton. Técnica, espaço, tempo: globalização e meio técnico-científico-informacional. São Paulo: Hucitec, 1994.

SANTOS, Milton. A natureza do espaço: técnica e tempo, razão e emoção. São Paulo: Edusp, 2006.

SANTOS, Milton. O espaço dividido: os dois circuitos da economia urbana dos países subdesenvolvidos. São Paulo: Edusp, 2008.

SILVA, Fredson Bernardino Araújo da. Metropolização do espaço na Amazônia Ocidental: discurso no contexto da Região Metropolitana de Manaus. In: ENANPEGE, 1., 2019, São Paulo. Anais [...]. São Paulo: [s. n.], 2019. p. 1-12. Disponível em:

https://www.enanpege2019.anpege.ggf.br/resources/anais/8/1562523770_ARQUIVO_ENAN PEGE_discurso_RMM1.pdf. Acesso em: $18 \mathrm{fev} .2020$.

SILVEIRA, María Laura. Finanças, consumo e circuitos da economia urbana na cidade de São Paulo. Caderno CRH, Salvador, v. 22, n. 55, p. 65-76, 2009. Disponível em: http://dx.doi.org/10.1590/S0103-49792009000100004. Acesso em: 18 fev. 2020.

SOUSA, Isaac. A ponte Rio Negro e a Região Metropolitana de Manaus: adequações no espaço urbano-regional à reprodução do capital. 2013. Tese (Doutorado em Geografia Humana) Faculdade de Filosofia, Letras e Ciências Humanas, Universidade de São Paulo, São Paulo, 2013.

SOUZA, Crizam G. Produção da moradia social na cidade de Parintins-AM: da Cohab-AM ao Minha casa minha vida - 1969 a 2017. 2018. Dissertação (Mestrado em Geografia) - Instituto de Filosofia, Ciências Humanas e Sociais, Universidade Federal do Amazonas, Manaus, 2018.

WARF, Barney. Digitalização, globalização e capital financeiro hipermóvel. GEOUSP: Espaço e Tempo, São Paulo, v. 21, n. 2, p. 397-406, out. 2017.

Recebido: abril de 2021.

Aceito: agosto de 2021. 